\title{
Refractory and metastatic infantile fibrosarcoma harboring LMNA-NTRK1 fusion shows complete and durable response to crizotinib
}

\author{
Jonathan Bender, ${ }^{1}$ Bailey Anderson, ${ }^{1}$ David A. Bloom, ${ }^{2}$ Raja Rabah, ${ }^{3}$ \\ Rhonda McDougall, ${ }^{1}$ Pankaj Vats, ${ }^{4}$ and Rajen Mody ${ }^{1,4,5}$ \\ ${ }^{1}$ Department of Pediatrics, ${ }^{2}$ Department of Radiology, ${ }^{3}$ Department of Pathology, ${ }^{4}$ Michigan Center \\ for Translational Pathology, ${ }^{5}$ Comprehensive Cancer Center, University of Michigan, Ann Arbor, \\ Michigan 48109, USA
}

\begin{abstract}
Infantile fibrosarcoma (IFS) is a rare soft-tissue sarcoma, which classically presents as an aggressive and rapidly enlarging tumor over the distal extremities of children in their first year of life. The presence of ETV6 and NTRK3 gene rearrangement is characteristic of IFS, which can be detected on routine fluorescence in situ hybridization (FISH) testing. Patients with IFS typically respond well to surgical resection and chemotherapy and have an overall survival of $\sim 90 \%$. In this report, we outline the use of integrative clinical sequencing (ICS) including RNA-seq in a patient with refractory, metastatic IFS to reveal an unusual fusion (LMNA-NTRK1), not detected by routine FISH testing, which was treated with oral crizotinib and resulted in a complete and durable long-term response. This study highlights the utility of ICS in identifying cryptic gene fusions, especially in refractory malignancies, and demonstrates how such information can be used to select targeted therapies in patients with actionable molecular alterations.
\end{abstract}

Corresponding author: rmody@med.umich.edu

(C) 2019 Bender et al. This article is distributed under the terms of the Creative Commons Attribution-NonCommercial License, which permits reuse and redistribution, except for commercial purposes, provided that the original author and source are credited.

Ontology terms: desmoid tumors

Published by Cold Spring Harbor Laboratory Press

doi:10.1101/mcs.a003376

\section{INTRODUCTION}

Infantile fibrosarcoma (IFS) is a soft-tissue sarcoma that arises in the first year of life and is the most common non-rhabdomyosarcoma in this age group (Sultan et al. 2010). IFS typically manifests as a nontender, rapidly enlarging, circular, erythematous mass over the distal extremities (Giovanni et al. 2001; Adibe et al. 2011). Histologically, IFS is characterized by fascicles of fairly uniform spindle-shaped cells with pale eosinophilic cytoplasm and high mitotic indices (Chung and Enzinger 1976). Classically, IFS is driven by the $t(12 ; 15)(p 13$; q25) translocation encoding the ETV6-NTRK3 fusion protein, as also seen in congenital mesoblastic nephroma (Knezevich et al. 1998; Rubin et al. 1998). Management consists of surgical resection, along with potentially neoadjuvant and adjuvant chemotherapy, with an overall 10-yr survival of $90 \%$; unlike its adult counterparts, IFS is marked by a typically robust response to chemotherapy (Orbach et al. 2010). Although local recurrence is common, distant metastasis is relatively unusual, with the most common metastatic site being the lungs (Chung and Enzinger 1976; Giovanni et al. 2001).

The neurotrophic receptor tyrosine kinase (NTRK1-3) family encodes tropomyosin receptor tyrosine kinase proteins (TRKA-C), which are involved in the regulation of neuronal cell 
proliferation, division, and differentiation (Vaishnavi et al. 2015). Although initially described in colorectal cancer in 1986, TRK fusions are now being increasingly identified in a number of pediatric and adult malignancies and may be present in 1\% of solid tumors (Martin-Zanca et al. 1986; Drilon et al. 2018). Given the prevalence of aberrant TRK signaling seen in a number of cancers, TRK inhibition represents an attractive therapeutic target. Crizotinib is a commercially available, oral tyrosine kinase inhibitor (TKI) that is approved by the FDA for the treatment of patients with locally advanced or metastatic non-small-cell lung cancer (NSCLC) with ALK gene rearrangements (Kazandjian et al. 2014). In addition to ALK inhibition, crizotinib has shown activity against the NTRK pathway (Taipale et al. 2013). Although IFS is typically characterized by ETV6-NTRK3 fusion, herein we present the case of a child with refractory, metastatic IFS whose tumor harbored a noncanonical LMNANTRK1 fusion only identified by next-generation sequencing (NGS), who achieved a durable, complete response with crizotinib therapy.

\section{CASE REPORT}

Our patient was noted at birth to have a mass on her left forearm. As the patient was adopted, extended family history was unknown. At $13 \mathrm{~d}$ of life, the patient underwent biopsy of the lesion at an outside hospital, which revealed a low-grade spindle cell proliferation with fascicular arrangement and myxoid background infiltrating fatty tissue resembling fibromatosis (Fig. 1A,B). The cellularity was low to moderate with no significant atypia or mitotic figures noted. Lesional cells were negative for myogenin and MYOD1 and revealed weak staining with smooth muscle actin (SMA). The lesion was classified as fibromatosis with the differential diagnosis including lipofibromatosis, although the possibility of the biopsy representing the edge of an IFS could not be excluded. Fluorescence in situ hybridization (FISH) for sarcoma translocations, including $t(12 ; 15)(p 13 ; q 25)$, was performed and was negative. A repeat larger biopsy with further cytogenetic workup was recommended but not pursued. At that time, the decision was made to observe only.

At age 2, the left forearm mass began to enlarge, and the patient underwent repeat resection of $>95 \%$ of the mass. Pathology from this sample (Fig. 1C) showed a more cellular spindle cell proliferation arranged in fascicles and sheets with hemangiopericytoma-like vascular channels with focal necrosis and increased mitotic figures. The peripheral areas were less cellular and showed some myxoid background, similar to the initial biopsy, resembling fibromatosis. Tumor cells were positive with SMA; S100 and Ki-67 highlighted $~ 10 \%$ positive nuclei. Desmin and epithelial membrane antigen were negative. The differential diagnosis at this stage included fibrosarcoma, spindle cell embryonal rhabdomyosarcoma, leiomyosarcoma, malignant peripheral nerve sheath tumor, and synovial sarcoma. Myogenin and MYOD1 were negative. FISH and RT-PCR were again negative for common sarcoma translocations including ETV6-NTRK3. Overall, the pathology was characterized as high-grade spindle cell sarcoma, Pediatric Oncology Group (POG) grade 3/3, with a negative metastatic workup. The patient's parents elected not to proceed with amputation, and instead treatment began with six cycles of ifosfamide and doxorubicin according to ARST0332 (not on study), along with radiation for local control. Four months following completion of therapy, she developed recurrence at the original tumor site, along with a new mass on the left hand. The patient underwent amputation of the left proximal forearm, including both masses, with pathology demonstrating high-grade spindle cell sarcoma consistent with prior. The patient's parents deferred additional chemotherapy because the patient was disease-free. Four months after amputation, routine imaging revealed two nodules in the right lung, which were biopsied and revealed metastatic high-grade sarcoma (Fig. 1D). She underwent two cycles of gemcitabine and docetaxel and an additional six cycles of vincristine, actinomycin, and cyclophosphamide. 

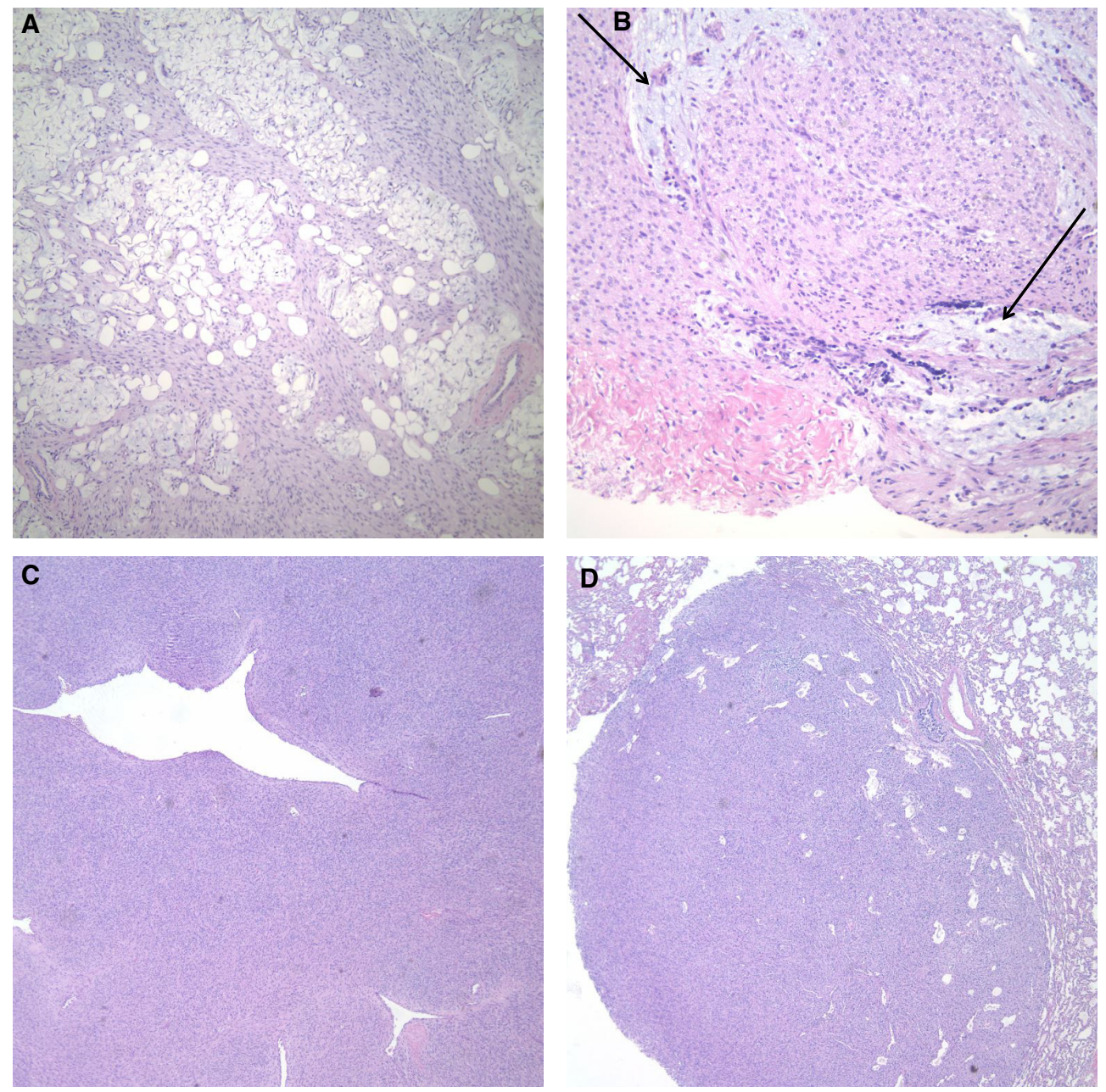

Figure 1. (A) Bland low-grade spindle cell proliferation infiltrating fat, 40×. (B) Tumor cells are round to ovoid with no significant atypia or mitotic figures. Focal myxoid areas present (arrows). (C) There is a spindle cell proliferation arranged in fascicles and sheets with some hemangiopericytoma-like vascular channels. (D) Lung with metastatic high-grade sarcoma.

Approximately 10 mo following completion of treatment, she was found to have multiple recurrent pulmonary nodules, with the largest nodule identified in the inferior aspect of the right middle lobe and measuring $8 \mathrm{~mm}$, but at least eight to10 nodules in both lungs (Fig. 2A,B). The patient was enrolled in the Peds-MiOncoSeq clinical sequencing study (UM-IRBMED HUM \#00056496) and underwent integrative sequencing as previously described (Mody et al. 2015). Briefly, paired-end whole-exome libraries from the patient's original biopsy at diagnosis were matched with normal DNA and with transcriptome libraries, which were prepared and sequenced. Aligned exome and transcriptome sequences were analyzed to detect putative somatic mutations, insertions and deletions (indels), copy number alterations, gene fusions, and gene expression. The patient's parents provided informed consent and received pre-enrollment genetic counseling.

Sequencing revealed a nonclassical LMNA-NTRK1 fusion (Fig. 3). Patient was presented at our multidisciplinary precision oncology tumor board; because none of the specific NTRK inhibitors was available for clinical use in children at the time of discussion, a consensus 

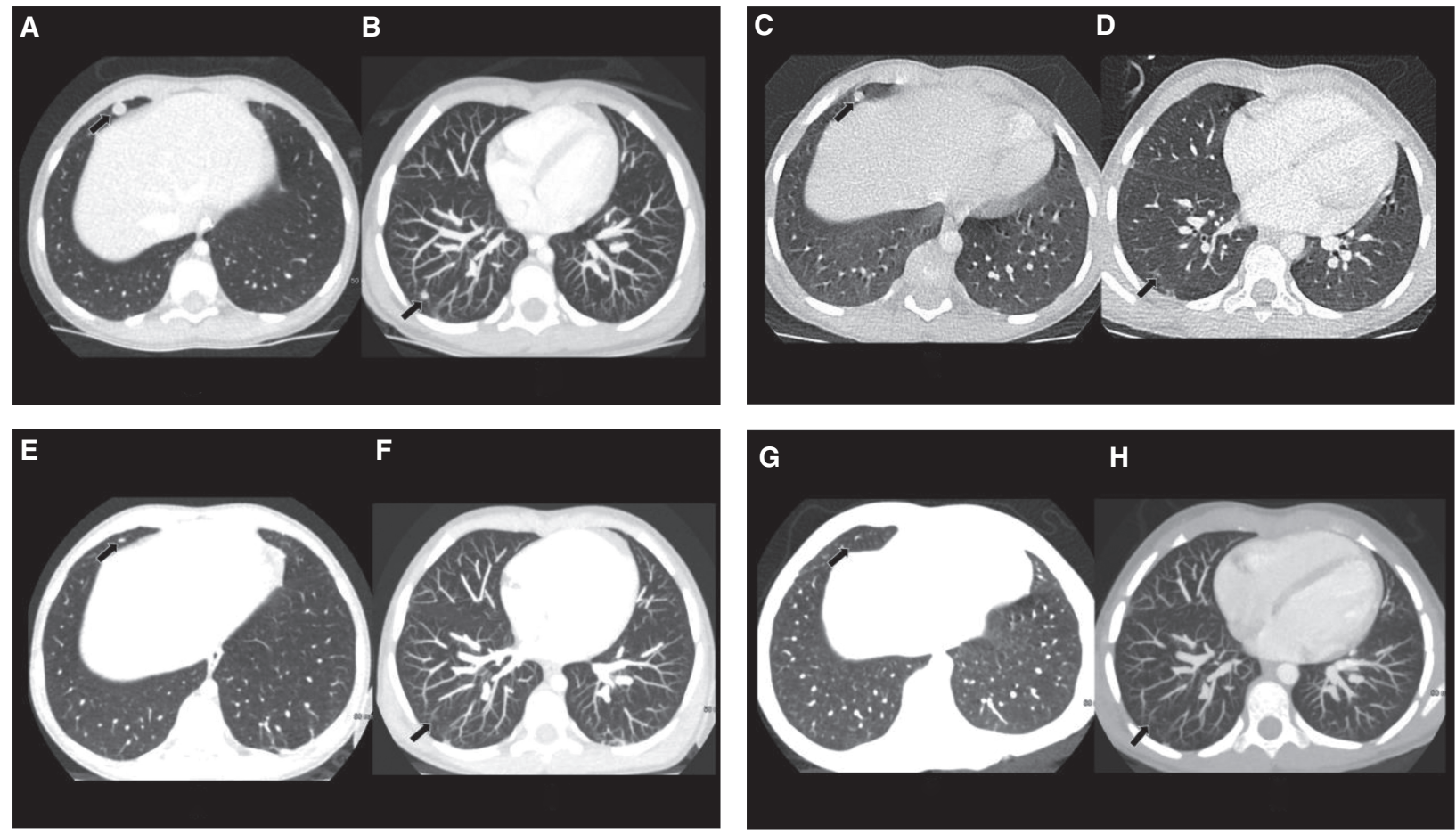

Figure 2. Initial recurrence before crizotinib therapy: $(A)$ a $0.63-\mathrm{mm}$ slice thickness spiral axial image of the chest with intravenous iodinated contrast demonstrates a well-defined 8-mm right middle lobe lung nodule consistent with metastatic disease (arrow); and (B) an 8-mm maximum intensity projection (MIP) image with clear delineation of a $4.5-\mathrm{mm}$ right lower lobe pulmonary metastasis in relationship to the pulmonary vasculature (arrow). Two months after initiation of crizotinib therapy: (C) a $0.63-\mathrm{mm}$ spiral axial image with reduction in the size of the right middle lobe nodule $(5.3 \mathrm{~mm}$, arrow); and $(D)$ a thin section axial image with decrease in size of the right lower lobe nodule, now $2.4 \mathrm{~mm}$ (arrow). Twenty-one months after initiation of crizotinib therapy: $(E)$ residual linear scarring is noted in the region of the original right middle lobe metastasis; and $(F)$ no clear residual nodule seen in the right lower lobe. Follow-up CT imaging (G, thin slice axial image; $H, M I P$ image) demonstrates complete resolution of the nodules $\sim 12$ mo after cessation of crizotinib therapy and $\sim 43$ mo since its introduction.

recommendation was made to initiate treatment with crizotinib $200 \mathrm{mg}$ BID. After 2 mo on crizotinib, a CT of the chest with intravenous contrast revealed a partial response with interval decrease in number and size of the pulmonary nodules, with the largest nodule in the right middle lobe having decreased in size to $5.3 \mathrm{~mm}$ (Fig. 2C,D). Treatment was tolerated well except for mild intermittent abdominal pain. A follow-up CT examination after 22 mo on therapy revealed complete resolution of the pulmonary nodules with residual scarring

LMNA

\begin{tabular}{|l|l||l|l|l|l|}
\hline & C1 & C2 & & LTD & \\
\hline
\end{tabular}

LMNA-NTRK1

\begin{tabular}{|l|l|l|l|}
\hline & C1 & TM & ETK \\
\hline
\end{tabular}

NTRK1

\begin{tabular}{|l|l|l|l|l|l||}
\hline & IgL & & IgL & TM & PTK \\
\hline
\end{tabular}

Figure 3. The LMNA-NTRK1 fusion protein encodes a coiled-coil dimerization domain of LMNA (exon 2, NM_170707) fused to the tyrosine kinase domain of NTRK1 (exon 10, NM_001012331). 
Table 1. Sequencing details of normal and tumor exome and tumor transcriptome

\begin{tabular}{|c|c|c|c|c|c|c|c|c|c|}
\hline \multicolumn{8}{|c|}{ Exomes } & \multirow{2}{*}{\multicolumn{2}{|c|}{$\begin{array}{c}\text { Transcriptomes } \\
\text { Tumor }\end{array}$}} \\
\hline \multicolumn{2}{|c|}{ No. of clusters } & \multicolumn{2}{|c|}{ Alignment (\%) } & \multicolumn{2}{|c|}{ Mean coverage $(x)$} & \multicolumn{2}{|c|}{ PCR duplication (\%) } & & \\
\hline Tumor & Reference & Tumor & Reference & Tumor & Reference & Tumor & Reference & No. of clusters & Alignment (\%) \\
\hline $110,706,636$ & $85,801,852$ & 96.7 & 93.6 & 187 & 140 & 4.2 & 3.5 & $107,818,594$ & 91.0 \\
\hline
\end{tabular}

PCR, polymerase chain reaction.

seen in both lungs including in the region of the prior right middle lobe nodule (Fig. 2E,F). Treatment with crizotinib was discontinued in May 2017, after 31 mo on treatment, because of parental request, and the patient remains in a durable complete response now $>18$ mo off therapy (Fig. 2G,H).

\section{GENOMIC ANALYSES}

Upon referral to our institution, the patient was enrolled in the Peds-MiOncoSeq study. Tissue from the patient's original tumor resection was submitted in two blocks containing at least $60 \%$ tumor cells for integrative clinical exome (tumor and germline DNA) and transcriptome (tumor RNA) sequencing, as previously described (Mody et al. 2015). Details of sequencing depth and quality are presented in Table 1, whereas other sequencing findings are summarized in Table 2. The results revealed copy loss at Chr 3q, copy gain at Chr 16, and homozygous deletion of CDKN2A and CDKN2B on Chr 9. Six total somatic mutations of unknown

Table 2. Somatic variants of potential significance identified in the patient

\begin{tabular}{|c|c|c|c|c|c|c|}
\hline Gene & Genomic location & $\begin{array}{l}\text { HGVS DNA } \\
\text { ref. }\end{array}$ & $\begin{array}{l}\text { HGVS } \\
\text { protein ref. }\end{array}$ & Variant type & Predicted effect & $\begin{array}{l}\text { dpSNP/ } \\
\text { dbVarID }\end{array}$ \\
\hline \multicolumn{7}{|c|}{ Rearrangement analysis } \\
\hline LMNA-NTRK1 & $\begin{array}{c}\text { 5'-junction: Chr } \\
\text { 1:156100565 } \\
\text { 3'-junction: Chr } \\
\text { 1:156844697 }\end{array}$ & N/A & $\mathrm{N} / \mathrm{A}$ & Inversion & $\begin{array}{l}\text { LMNA-NTRK1 in- } \\
\text { frame fusion }\end{array}$ & N/A \\
\hline \multicolumn{7}{|c|}{ Copy number variations } \\
\hline CDKN2A & Chr 9 & N/A & N/A & $\begin{array}{l}\text { Homozygous } \\
\text { deletion }\end{array}$ & $\begin{array}{r}\text { Deletion of } \\
\text { CDKN2A }\end{array}$ & N/A \\
\hline$C D K N 2 B$ & Chr 9 & N/A & N/A & $\begin{array}{l}\text { Homozygous } \\
\text { deletion }\end{array}$ & $\begin{array}{r}\text { Deletion of } \\
\text { CDKN2B }\end{array}$ & N/A \\
\hline Chr 3q & Chr 3 & $\mathrm{~N} / \mathrm{A}$ & $\mathrm{N} / \mathrm{A}$ & Copy loss & Loss of $3 q$ & N/A \\
\hline Chr 16 & Chr 16 & N/A & N/A & Copy gain & Gain of 16 & N/A \\
\hline \multicolumn{7}{|c|}{ Single nucleotide variants (of unknown significance) } \\
\hline $\begin{array}{l}\text { FAM20A } \\
\text { NM_017565.3 }\end{array}$ & Chr 17:66596677 & c. $131 \mathrm{G}>\mathrm{A}$ & p.Cys44Tyr & Substitution & Missense & N/A \\
\hline $\begin{array}{l}\text { HIST1H3I } \\
\text { NM_003533.2 }\end{array}$ & Chr 6:27839829 & c. $265 \mathrm{G}>\mathrm{T}$ & p.Ala89Ser & Substitution & Missense & N/A \\
\hline $\begin{array}{l}\text { ZNF595 } \\
\text { NM_182524.3 }\end{array}$ & Chr 4:87313 & c.1916dupA, & p.Asp639fs & Substitution & Frameshift & rs60154095 \\
\hline $\begin{array}{l}\text { TMEM179 } \\
\text { NM_001286389.1 }\end{array}$ & Chr 14:105071002 & c.77T>C & p.Val26Ala & Substitution & Missense & N/A \\
\hline
\end{tabular}


significance were identified affecting STAG2, PKD1, FAM2OA, HIST1H3I, RP11-614O9.3.1, and TMEM179. Although the canonical ETV6-NTRK3 fusion was not detected, a LMNANTRK 1 fusion was identified on both RNA sequencing and DNA-based hybridization capture. Correspondingly, increased RNA expression was noted of both NTRK1 and LMNA.

\section{DISCUSSION}

Herein we present the case of a child with refractory, metastatic IFS harboring an unusual LMNA-NTRK1 fusion, not detected by routine FISH studies, who was successfully treated with crizotinib. To our knowledge, this is the first publication reporting a complete and durable response of more than 48 mo to crizotinib therapy in a patient with metastatic, refractory IFS.

Rather than harboring the pathognomonic ETV6-NTRK3 fusion, our patient presented with a nonclassical LMNA-NTRK1 fusion. LMNA encodes proteins lamin A and lamin C, which are involved in the nuclear envelope structure. The LMNA-NTRK1 fusion protein encodes a coiled-coil dimerization domain of LMNA fused to the tyrosine kinase domain of NTRK1. LMNA-NTRK1 fusions have been implicated in a number of malignancies, including Spitz nevi (Wiesner et al. 2014), colorectal cancer (Sartore-Bianchi et al. 2015), lung cancer (Vaishnavi et al. 2013), soft-tissue sarcomas (Florian et al. 2016; Wong et al. 2016; Kohsaka et al. 2018), and a rare case of infantile-onset lipofibromatosis-like neural tumor (Bartenstein et al. 2018).

Within the past 2 years, there have been additional case reports of LMNA-NTRK 1 fusions in pediatric soft-tissue sarcomas and IFS. One recent article reported two pediatric soft-tissue sarcomas with similar fusions, including LMNA-NTRK1 or TPM3-NTRK1, in which pathology revealed a consistent pattern of myopericytic and hemangiopericytic histologic features, along with high mitotic rates, similar to the pathologic description of the case presented herein (Florian et al. 2016). In contrast to our patient, neither patient in their series had metastatic progression. LMNA-NTRK1 fusion was additionally identified in a 6-yr-old with a forearm mass; however, histology revealed few mitotic figures without a hemangiopericytic appearance (Kohsaka et al. 2018). In a recent large study of pediatric tumor specimens, two cases harbored LMNA-NTRK1 fusions (Pavlick et al. 2017). Of the two patients with LMNA-NTRK1 fusions, one was a 1-yr-old with metastatic fibrosarcoma, the other patient was a 14-yr-old with PNET. Similarly, in a recent case series of six infants with lesions resembling IFS without ETV6-NTRK3 fusion, one of the patients tested positive for LMNA-NTRK1 fusion (Davis et al. 2018). Most notably, Wong et al. reported on a similar case of metastatic IFS that tested positive for LMNA-NTRK1, although pathology did not reveal a hemangiopericytic pattern as seen in our case and in the series by Florian et al. After progressing despite multiple chemotherapies, their patient was started on crizotinib and had a dramatic partial response to treatment (Wong et al. 2016). Of note, as in our case presented here, coincident CDKN2A deletions have been found in a significant number of the above patients who harbor NTRK1 fusions, including three of four cases (Florian et al. 2016), two of four cases (Pavlick et al. 2017), three of five cases (Doebele et al. 2015), and in Wong's case above (Wong et al. 2016).

NTRK fusions are being increasingly implicated in a number of malignancies in both pediatric and adult patients, including pediatric high-grade glioma (Wu et al. 2014), soft-tissue sarcomas (Florian et al. 2016), secretory breast cancer (Tognon et al. 2002), and papillary thyroid cancer (Greco et al. 2010), in addition to many other solid tumors (Stransky et al. 2014). The case presented herein fits nicely into the evolving landscape of noncanonical NTRK fusions, which are being increasingly identified in pediatric soft-tissue sarcomas. In a study of 2031 pediatric tumor specimens, NTRK fusions were identified in nine cases $(0.44 \%)$, 
including three ETV6-NTRK3, one TGF-NTRK3, one SQSTM1-NTRK1, one TPM3-NTRK1, one TPR1-NTRK1, and two LMNA-NTRK1 as cited above (Pavlick et al. 2017). There have been three additional patients reported with IFS harboring EML4-NTRK3 fusions rather than the classic ETV6-NTRK3 fusion, as well (Tannenbaum-Dvir et al. 2015; Church et al. 2017; Kao et al. 2018). Consistently, in a recent article of 10 patients with ETV6-NTRK3 fusion-negative spindle cell sarcomas with pathology reminiscent of IFS, testing revealed one EML4-NTRK3 fusion and one TPM3-NTRK1 fusion (Kao et al. 2018).

Crizotinib is an oral TKI, which has been shown to have in vitro activity against the ETV6NTRK3 fusion protein, along with specific inhibition of TRKA (Taipale et al. 2013; Vaishnavi et al. 2013). Given the increasing awareness of aberrant TRK signaling in a wide number of malignancies, selective TRK inhibitors are currently in early-phase clinical trials, with positive initial results. The first published report centered on a targeted TRK inhibitor, larotrectinib (LOXO-101), which produced rapid response in an adult patient with soft-tissue sarcoma harboring the LMNA-NTRK1 fusion (Doebele et al. 2015). Recently, a phase I trial of 55 adult and pediatric patients harboring TRK fusion-positive tumors showed significant and durable efficacy in patients of all ages, including seven patients with IFS (Drilon et al. 2018). Moreover, a recent study of five pediatric patients with locally advanced sarcomas with TRK fusions demonstrated partial response to neoadjuvant larotrectinib resulting in less extensive and morbid surgical resections (DuBois et al. 2018).

As our ability to develop effective targeted treatments continues to advance rapidly, so too does the need grow for adequate molecular characterization of each patient's tumor. It is becoming increasingly evident that aberrant NTRK signaling plays a vital role in mediating solid tumors in both pediatric and adult patients. Through NGS, we were able to identify and to target a noncanonical LMNA-NTRK1 fusion protein in our patient, not detected by FISH or RT-PCR, and subsequently to induce a durable and complete response with crizotinib, despite our patient having previously failed multiple resections and chemotherapeutic agents. As NGS technology is not yet easily accessible to all patients, other research groups have published on the feasibility of using pan-Trk immunohistochemistry to identify NTRK rearrangements in pediatric mesenchymal cancers rather than relying on standard FISH and RT-PCR panels, which miss nonclassical NTRK rearrangements, as was the case initially for our patient (Rudzinski et al. 2018).

Given the growing recognition of NTRK fusions in a variety of tumors, especially soft-tissue sarcomas, further work will be required to characterize the histologic, molecular, and clinical signatures of such malignancies. Whether soft-tissue sarcomas of infancy harboring nonclassical NTRK fusions represent a distinct clinical entity from IFS showing the canonical ETV6-NTRK3 fusion also remains to be further investigated. Although phase I trials of targeted TRK inhibitors show promise, the widespread clinical availability of such agents remains far off. In pediatric patients with soft-tissue sarcomas harboring NTRK fusions refractory to standard treatments, oral crizotinib may be a reasonable and effective therapeutic option for inducing complete and durable response while eagerly awaiting clinical deployment of selective TRK inhibitors.

\section{ADDITIONAL INFORMATION}

\section{Data Deposition and Access}

All somatic mutation information generated from this study has been uploaded to $\mathrm{dbGaP}$ (https://www.ncbi.nlm.nih.gov/gap) under accession number phs000673.v2.p1. The interpreted variants were deposited to ClinVar (https://www.ncbi.nlm.nih.gov/clinvar/) and can be found under accession number SCV000864230. 
Competing Interest Statement The authors have declared no competing interest.

Received August 15, 2018; accepted in revised form December 14, 2018.

\section{Ethics Statement}

The parents provided informed consent, the patient provided written assent, and the family received mandatory pre-enrollment genetic counseling. The patient was enrolled on a prospective integrative clinical sequencing trial (Peds-MiOncoSeq) approved by the University of Michigan Medical Institutional Review Board (UM-IRBMED HUM \#00056496) (Mody et al. 2015).

\section{Acknowledgments}

The authors would like to thank the patient and her family who participated in this study.

\section{Author Contributions}

R.M. developed the study concept and design and provided funding. R.M., B.A., J.B., D.A.B., R.R., and R.Mc. analyzed and interpreted the data. B.A., D.A.B., R.R., and J.B. developed the figures, R.M. and R.Mc. cared for the patient, J.B., B.A., D.B., R.R., R.Mc., and R.M. drafted and edited the manuscript.

\section{Funding}

We acknowledge the support by the National Institutes of Health (NIH) Clinical Sequencing Exploratory Research (CSER) Award NIH 1UM1HG006508. R.M. is a Hyundai Hope on Wheels Scholar.

\section{REFERENCES}

Adibe OO, Juang D, Valusek PA, Holcomb GW III, Snyder CL. 2011. Infantile fibrosarcoma: 2 case reports and literature review. Eur J Pediatr Surg 21: 200-202. doi:10.1055/s-0031-1271734

Bartenstein DW, Coe TM, Gordon SC, Friedmann AM, Senna MM, Kelleher CM, Antonescu CR, Nazarian RM, Hawryluk EB. 2018. Lipofibromatosis-like neural tumor: case report of a unique infantile presentation. JAAD Case Rep 4: 185-188. doi:10.1016/j.jdcr.2017.09.004

Chung EB, Enzinger FM. 1976. Infantile fibrosarcoma. Cancer 38: 729-739. doi:10.1002/1097-0142(197608) 38:2<729::AID-CNCR2820380216>3.0.CO;2-Z

Church AJ, Calicchio ML, Nardi V, Skalova A, Pinto A, Dillon DA, Gomez-Fernandez C, Manoj N, Haimes JD, Stahl JA, et al. 2017. Recurrent EML4-NTRK3 fusions in infantile fibrosarcoma and congenital mesoblastic nephroma suggest a revised testing strategy. Mod Pathol 31: 463-473. doi:10.1038/modpathol.2017.127

Davis JL, Lockwood CM, Albert CM, Tsuchiya K, Hawkins DS, Rudzinski ER. 2018. Infantile NTRK-associated mesenchymal tumors. Pediatr Dev Pathol 21: 68-78. doi:10.1177/1093526617712639

Doebele RC, Davis LE, Vaishnavi A, Le AT, Estrada-Bernal A, Keysar S, Jimeno A, Varella-Garcia M, Aisner DL, $\mathrm{Li} Y$, et al. 2015. An oncogenic NTRK fusion in a soft tissue sarcoma patient with response to the tropomyosin-related kinase (TRK) inhibitor LOXO-101. Cancer Discov 5: 1049-1057. doi:10.1158/2159-8290.CD$15-0443$

Drilon A, Laetsch TW, Kummar S, DuBois SG, Lassen UN, Demetri GD, Nathenson M, Doebele RC, Farago AF, Pappo AS, et al. 2018. Efficacy of larotrectinib in TRK fusion-positive cancers in adults and children. N Engl J Med 378: 731-739. doi:10.1056/NEJMoa1714448

DuBois SG, Laetsch TW, Federman N, Turpin BK, Albert CM, Nagasubramanian R, Anderson ME, Davis JL, Qamoos HE, Reynolds ME, et al. 2018. The use of neoadjuvant larotrectinib in the management of children with locally advanced TRK fusion sarcomas. Cancer 124: 4241-4247. doi:10.1002/cncr.31701

Florian H, Jasmin K, Anne A, Matthias B, Kortine K, Matthias S, Moskalev Evgeny A, Rainer W, Satir AA, Abdelmagid lbtihalat $\mathrm{E}$, et al. 2016. Paediatric and adult soft tissue sarcomas with NTRK1 gene fusions: a subset of spindle cell sarcomas unified by a prominent myopericytic/haemangiopericytic pattern. $J$ Pathol 238: 700-710. doi:10.1002/path.4701

Giovanni C, Modesto C, Rita A, Dall'Igna P, Gianni B, Giovanni S, Ilaria Z, Gianfranco D, Alessandro I, Fortunato $S$, et al. 2001. Fibrosarcoma in pediatric patients: results of the Italian cooperative group studies (19791995). J Surg Oncol 78: 225-231. doi:10.1002/jso.1157

Greco A, Miranda C, Pierotti MA. 2010. Rearrangements of NTRK1 gene in papillary thyroid carcinoma. Mol Cell Endocrinol 321: 44-49. doi:10.1016/j.mce.2009.10.009 
Kao YC, Fletcher CDM, Alaggio R, Wexler L, Zhang L, Sung YS, Orhan D, Chang WC, Swanson D, Dickson BC, et al. 2018. Recurrent BRAF gene fusions in a subset of pediatric spindle cell sarcomas: expanding the genetic spectrum of tumors with overlapping features with infantile fibrosarcoma. Am J Surg Pathol 42: 2838. doi:10.1097/PAS.0000000000000938

Kazandjian D, Blumenthal GM, Chen HY, He K, Patel M, Justice R, Keegan P, Pazdur R. 2014. FDA approval summary: crizotinib for the treatment of metastatic non-small cell lung cancer with anaplastic lymphoma kinase rearrangements. Oncologist 19: e5-e11. doi:10.1634/theoncologist.2014-0241

Knezevich SR, Garnett MJ, Pysher TJ, Beckwith JB, Grundy PE, Sorensen PH. 1998. ETV6-NTRK3 gene fusions and trisomy 11 establish a histogenetic link between mesoblastic nephroma and congenital fibrosarcoma. Cancer Res 58: 5046-5048.

Kohsaka S, Saito T, Akaike K, Suehara Y, Hayashi T, Takagi T, Kaneko K, Ueno T, Kojima S, Kohashi KI, et al. 2018. Pediatric soft tissue tumor of the upper arm with LMNA-NTRK1 fusion. Hum Pathol 72: 167-173. doi:10.1016/j.humpath.2017.08.017

Martin-Zanca D, Hughes SH, Barbacid M. 1986. A human oncogene formed by the fusion of truncated tropomyosin and protein tyrosine kinase sequences. Nature 319: 743-748. doi:10.1038/319743a0

Mody R, Wu Y, Lonigro R, Cao X, Roychowdhury S, Vats P, Frank K, Prensner J, Asangani I, Palanisamy N, et al. 2015. Integrative clinical sequencing in the management of refractory or relapsed cancer in youth. JAMA 314: 913-925. doi:10.1001/jama.2015.10080

Orbach D, Rey A, Cecchetto G, Oberlin O, Casanova M, Thebaud E, Scopinaro M, Bisogno G, Carli M, Ferrari A. 2010. Infantile fibrosarcoma: management based on the European experience. J Clin Oncol 28: 318323. doi:10.1200/JCO.2009.21.9972

Pavlick D, Schrock AB, Malicki D, Stephens PJ, Kuo DJ, Ahn H, Turpin B, Allen JM, Rosenzweig M, Badizadegan K, et al. 2017. Identification of NTRK fusions in pediatric mesenchymal tumors. Pediatr Blood Cancer 64: e26433. doi:10.1002/pbc.26433

Rubin BP, Chen C, Morgan TW, Xiao S, Grier HE, Kozakewich HP, Perez-Atayde A, Fletcher JA. 1998. Congenital mesoblastic nephroma t(12;15) is associated with ETV6-NTRK3 gene fusion: cytogenetic and molecular relationship to congenital (infantile) fibrosarcoma. Am J Pathol 153: 1451-1458. doi:10.1016/ S0002-9440(10)65732-X

Rudzinski ER, Lockwood CM, Stohr BA, Vargas SO, Sheridan R, Black JO, Rajaram V, Laetsch TW, Davis JL. 2018. Pan-Trk immunohistochemistry identifies NTRK rearrangements in pediatric mesenchymal tumors. Am J Surg Pathol 42: 927-935. doi:10.1097/PAS.0000000000001062

Sartore-Bianchi A, Ardini E, Bosotti R, Amatu A, Valtorta E, Somaschini A, Raddrizzani L, Palmeri L, Banfi P, Bonazzina $E$, et al. 2015. Sensitivity to entrectinib associated with a novel LMNA-NTRK1 gene fusion in metastatic colorectal cancer. J Natl Cancer Inst 108: djv306. doi:10.1093/jnci/djv306

Stransky N, Cerami E, Schalm S, Kim JL, Lengauer C. 2014. The landscape of kinase fusions in cancer. Nat Commun 5: 4846. doi:10.1038/ncomms5846

Sultan I, Casanova M, Al-Jumaily U, Meazza C, Rodriguez-Galindo C, Ferrari A. 2010. Soft tissue sarcomas in the first year of life. Eur J Cancer 46: 2449-2456. doi:10.1016/j.ejca.2010.05.002

Taipale M, Krykbaeva I, Whitesell L, Santagata S, Zhang J, Liu Q, Gray NS, Lindquist S. 2013. Chaperones as thermodynamic sensors of drug-target interactions reveal kinase inhibitor specificities in living cells. Nat Biotechnol 31: 630-637. doi:10.1038/nbt.2620

Tannenbaum-Dvir S, Glade Bender JL, Church AJ, Janeway KA, Harris MH, Mansukhani MM, Nagy PL, Andrews SJ, Murty WV, Kadenhe-Chiweshe A, et al. 2015. Characterization of a novel fusion gene EML4NTRK3 in a case of recurrent congenital fibrosarcoma. Cold Spring Harb Mol Case Stud 1: a000471. doi: $10.1101 / \mathrm{mcs} . \mathrm{a} 000471$

Tognon C, Knezevich SR, Huntsman D, Roskelley CD, Melnyk N, Mathers JA, Becker L, Carneiro F, MacPherson $\mathrm{N}$, Horsman D, et al. 2002. Expression of the ETV6-NTRK3 gene fusion as a primary event in human secretory breast carcinoma. Cancer Cell 2: 367-376. doi:10.1016/S1535-6108(02)00180-0

Vaishnavi A, Capelletti M, Le AT, Kako S, Butaney M, Ercan D, Mahale S, Davies KD, Aisner DL, Pilling AB, et al. 2013. Oncogenic and drug sensitive NTRK1 rearrangements in lung cancer. Nat Med 19: 1469-1472. doi:10.1038/nm.3352

Vaishnavi A, Le AT, Doebele RC. 2015. TRKing down an old oncogene in a new era of targeted therapy. Cancer Discov 5: 25-34. doi:10.1158/2159-8290.CD-14-0765

Wiesner T, He J, Yelensky R, Esteve-Puig R, Botton T, Yeh I, Lipson D, Otto G, Brennan K, Murali R, et al. 2014. Kinase fusions are frequent in Spitz tumors and spitzoid melanomas. Nat Commun 5: 3116. doi:10.1038/ ncomms4116

Wong V, Pavlick D, Brennan T, Yelensky R, Crawford J, Ross JS, Miller VA, Malicki D, Stephens PJ, Ali SM, et al. 2016. Evaluation of a congenital infantile fibrosarcoma by comprehensive genomic profiling reveals an LMNA-NTRK1 gene fusion responsive to crizotinib. J Natl Cancer Inst 108: djv307. doi:10.1093/jnci/djv307

Wu G, Diaz AK, Paugh BS, Rankin SL, Ju B, Li Y, Zhu X, Qu C, Chen X, Zhang J, et al. 2014. The genomic landscape of diffuse intrinsic pontine glioma and pediatric non-brainstem high-grade glioma. Nat Genet 46: 444-450. doi:10.1038/ng.2938 


\section{COLD SPRING HARBOR Molecular Case Studies}

\section{Refractory and metastatic infantile fibrosarcoma harboring LMNA- NTRK1 fusion shows complete and durable response to crizotinib}

Jonathan Bender, Bailey Anderson, David A. Bloom, et al.

Cold Spring Harb Mol Case Stud 2019, 5: a003376

Access the most recent version at doi: $10.1101 /$ mcs.a003376

References

License

Email Alerting Service
This article cites 32 articles, 6 of which can be accessed free at: http://molecularcasestudies.cshlp.org/content/5/1/a003376.full.html\#ref-list-1

This article is distributed under the terms of the Creative Commons Attribution-NonCommercial License, which permits reuse and redistribution, except for commercial purposes, provided that the original author and source are credited.

Receive free email alerts when new articles cite this article - sign up in the box at the top right corner of the article or click here. 